\title{
O processo de Bolonha da Europa torna-se global: modelo, mercado, mobilidade, força intelectual ou estratégia para construção do Estado?*
}

\author{
Susan L. Robertson \\ Centre for Globalisation, Education and Societies
}

Tradução: Alfredo Macedo Gomes e Roderick Somerville Kay

\section{Introdução}

Em muitas partes do mundo, a educação superior é vista como um motor para o desenvolvimento de uma economia baseada no conhecimento; as políticas, os programas e as práticas da educação superior são cada vez mais cooptados e dimensionados por interesses políticos e econômicos geoestratégicos mais amplos. As pesquisas acadêmicas e as análises de políticas, no entanto, ainda tendem a negar a interconectividade global desse desenvolvimento de políticas, concebendo a educação superior em termos específicos em nível nacional ou regional, ou empregando tipologias simples que reduzem os sistemas de educação superior, por exemplo, a nações “exportadoras” ou "importadoras” de políticas e programas (OCDE, 2004). Essas

* Agradeço aos organizadores da $31^{\text {a }}$ Reunião da ANPEd pelo generoso convite para apresentar este trabalho, e ao meu colega professor Alfredo Macedo Gomes não apenas por facilitar minha presença, mas também pelo seu generoso engajamento neste projeto. abordagens limitam nossa compreensão das densas e complexas articulações e das interações entre os setores da educação superior, as políticas econômicas e os interesses regionais que são gerados por estratégias competitivas multiescalares e por influências globais sobre a educação superior.

Nessa perspectiva, este trabalho examina a interligação progressiva dos espaços da política de educação superior no mundo, focalizando em particular a Europa e seu projeto de globalizar a educação superior, assim como as implicações desse projeto para outras economias nacionais e regionais. O trabalho começa com o Espaço Europeu de Educação Superior, esboçando as principais características do competitivo projeto europeu naquele nível de educação. Apresenta-se como processo multilateral de Bolonha, projetado para criar uma arquitetura unificada de educação superior na Europa; foi remodelado e dirigido pela estratégia Lisboa 2000 da União Europeia (UE) para a competitividade e pelo relançamento da Agenda (também chamada de Estratégia) de Lisboa 2005. Defendo, primeiramente, 
que a estratégia redesenhada de Lisboa confirmou uma linguagem neoliberal de competitividade econômica nas políticas de educação superior na Europa. Segundo, mostro como essa agenda tem permitido a utilização da educação superior como uma plataforma para amplas estratégias de regionalização e globalização da UE. Essa seção do artigo relata como a educação superior tornou-se estrategicamente importante para a UE na criação tanto de "mentes" quanto de "mercados" para a economia europeia de conhecimento. Em seguida, exploro o modo como a gama crescente de iniciativas educacionais no nível europeu tem repercutido - direta e indiretamente - nos espaços nacionais de educação superior, incluindo países e regiões como os Estados Unidos, a Austrália, a América Latina, o sudeste da Ásia e assim por diante. O processo de regionalização na educação superior, promovido pelos atores no nível europeu, vem provocando consternação considerável em países como Estados Unidos e Austrália, os quais vêm tradicionalmente desfrutando da maior parte da indústria de exportação da educação superior. Suas ações e reações, portanto, são complexas e dimensionadas por interesses tanto endógenos quanto exógenos (Quintin, 2006; Ferrero-Waldner, 2005).

$\mathrm{Na}$ seção final, examino como as pressões internas coincidiram com essas influências e as relações externas para criar um "ponto de viragem” crítico nos entendimentos globais das relações internacionais na educação superior. O projeto europeu de educação superior, que é cada vez mais percebido como tendo algum significado para a economia mundial, vem desencadeando uma série de reações dinâmicas em países como a Austrália e os Estados Unidos, o que está levando a múltiplas novas lógicas e novos imaginários sobre o panorama global da educação superior. Com isso, está emergindo um sistema global mais integrado e relacional de educação superior. Eu também reflito sobre por que a Europa tende a priorizar as regiões como um meio para fazer avançar seus interesses geoestratégicos, sugerindo que as novas relações regionais fornecem uma plataforma para a Europa atuar à maneira de um Estado.

\section{Conhecimento, economia, Europa: os primórdios}

A criação de uma Europa coerente e competitiva teve seus antecedentes na década de 1950, e as iniciativas de educação superior exerceram papel importante desde o início (Corbett, 2005; Hingel, 2001). Contudo, a partir daquela década até o início dos anos de 1990, o projeto de educação superior da UE era quase inteiramente orientado para o interior, em sua ontologia e seus resultados. Com a notável exceção do Reino Unido (e, em menor medida, da França e da Alemanha), a “internacionalização” de programas de estudos, currículos, mobilidade estudantil e trajetórias de carreira da pesquisa foi essencialmente orientada para os parceiros europeus e os processos de europeização. Marcadoreschave durante esse período foram a institucionalização de reuniões regulares entre os ministros europeus de educação; a criação do Instituto Universitário Europeu, em Florença, em 1971; e o estabelecimento do programa de mobilidade Erasmus, da UE, em 1987, o que facilitou a circulação de estudantes e professores entre universidades dos Estados-membros.

Os objetivos principais incorporados nessas iniciativas de nível europeu eram produzir cidadãos com visão europeia engajados com a comunidade em expansão (e com a Comissão Europeia) e comprometidos com o conceito de cultura e valores “europeus". Delors, no entanto, também "tinha uma ideia altamente desenvolvida de educação e do papel que ela poderia desempenhar na sua estratégia para o avanço da integração europeia através do mercado único” (Corbett, 2005, p. 121). Assim, emergiram duas preocupações que parecia que programas de educação superior poderiam mediar: como criar um Mercado Único Europeu, por um lado, e um cidadão europeu, por outro. Atrelado o compromisso ao projeto europeu, era visto como essencial para combater o "nacionalismo estreito”, um impedimento para o avanço da Europa como um projeto político.

Em 1992, um mercado único e a UE foram anunciados pelo Tratado da União Europeia e assinados em Maastricht pelos chefes de Estado dos Estados- 
membros da Comunidade Europeia. O Tratado de Maastricht reconheceu o papel direto da União Europeia em matéria de educação, enquanto tentava enquadrar rigorosamente o espaço de manobra da Comissão Europeia, limitando a ação no nível europeu a atividades “suplementares”. Enquanto o Tratado de Maastricht pareceu sugerir que o papel da UE seria modesto, sob Delors a Comissão Europeia tinha ambições de desenvolver uma política mais abrangente para a educação superior em escala europeia.

O Memorando sobre Educação Superior de 1991 mostra que a educação superior "já tinha se tornado parte da ampla agenda de coesão econômica e social da Comunidade” (Huisman \& Wende, 2004, p. 350). A comissão rapidamente fez uma avaliação interna dos programas da UE e elaborou nova estratégia para explorar as oportunidades abertas pelo reconhecimento do Tratado de Maastricht da “dimensão europeia” em matéria de educação. A comissão também começou a olhar para fora, para além da região. Estabeleceu programas de colaboração de educação superior com países não-membros da UE por meio de iniciativas como: o programa Alfa, na América Latina; a elaboração do programa Tempus de cooperação com outros países Bálcãs Ocidentais, Europa Oriental, Ásia Central e os países vizinhos do Mediterrâneo; e relações ÁsiaEuropa por meio de estruturas inter-regionais, como a Asia-Link (Robertson, 2008b). No entanto, nessa altura, esses programas tenderam a ser baseados na cooperação cultural e nos objetivos de intercâmbio, e não foram bem coordenados com o emergente programa de políticas para a educação dentro da Europa.

Para compreender bem a política por trás do memorando e dos acontecimentos que se seguiram, é fundamental considerar a natureza mutante do contexto econômico e geopolítico mais amplo no qual os Estados-membros de Europa encontraram-se. Em 19911992, as maiores economias (incluindo a Alemanha) vivenciaram uma recessão que aumentou o número de diplomados desempregados na Europa (Teichler \& Kehm, 1995). Isso proporcionou alguma legitimidade para o projeto de educação superior da Comissão Europeia (CE). No entanto, de maior importância foram as mudanças mais amplas que estavam ocorrendo na economia global em função da globalização da economia, da transnacionalização da produção e dos mercados financeiros em nível material e o deslocamento, em nível ideológico, do keynesianismo para o neoliberalismo. Estas mudanças estruturais na economia global tiveram implicações diretas para a UE no sentido de que influenciaram diretamente sua reestruturação. Para ser competitiva na economia global, a Europa teve de se transformar na direção do livre comércio e de um mercado livre. Como Bieler e Morton defendem,

\section{[...] a desregulamentação dos mercados financeiros nacionais foi institucionalizada no Programa do Mercado Interno [...] enquanto a mudança para o neoliberalismo foi expressa pela própria natureza do programa do Mercado Interno e da sua ânsia para a liberalização e os critérios de convergência neoliberais da UME [União Monetária Europeia], focando na inflação baixa e na estabilidade de preços. (2001, p. 5)}

O imperativo para a Europa progredir como um projeto político e econômico de modo mais geral, e como uma economia baseada no conhecimento mais especificamente, está ligado aos Estados Unidos e ao declínio da participação da Europa na produção mundial de bens. Por esse motivo, os Estados Unidos e a UE partilham um interesse comum na expansão da economia de serviços globais - incluindo a educação superior como um mercado, como um motor para a inovação e um setor-chave no desenvolvimento de novas formas de propriedade intelectual. E, como Hartmann (2008, p. 210-211) observa, enquanto os Estados Unidos dominam o comércio mundial de serviços comerciais - com 14,3\% da proporção do mundo (World Trade Organization, 2007, p. 12) -, a proporção conjunta dos Estados-membros europeus (agora 27 deles) gera em torno de 46\%. Essa proporção tem aumentado a aspiração e a capacidade da UE para também estabelecer padrões para a emergente economia global de serviços, dando maior impulso à luta entre a Europa e os Estados Unidos no fornecimento de liderança normativa sobre o desenvolvimento de uma economia baseada em serviços. 


\section{Nova Estratégia de Lisboa e um Processo de Bolonha expansivo: visões e mecanismos}

Em 2000, as atividades educacionais da União Europeia receberam impulso significativo com a "Estratégia de Lisboa"; parte de uma plataforma econômica mais ampla da UE, que notoriamente declarou que a União Europeia deveria tornar-se a economia baseada no conhecimento mais competitiva e dinâmica do mundo, capaz de crescimento econômico sustentável com mais e melhores empregos e uma maior coesão social. A Estratégia de Lisboa forneceu o mandato e uma pauta para estender o alcance de uma profunda responsabilidade da política da Europa em território nacional - na educação - e, por fim, para fora, para o resto do mundo. A Estratégia de Lisboa confirmou uma compreensão neoliberal da contribuição da educação superior para o bem-estar socioeconômico da região: a construção e a retenção de capital humano. Em janeiro de 2000, sob a proposta da Comissão Europeia, foi tomada a decisão de estabelecer uma Área Europeia de Pesquisa e Inovação (ERIA em inglês), com o objetivo central e explícito de apoiar uma economia baseada no conhecimento em escala europeia sob o signo de uma "Europa do Conhecimento".

A Agenda Lisboa 2000 para a educação superior foi acompanhada paralelamente pelo Processo de Bolonha: um projeto de destaque e ambicioso impulsionado pelos governos nacionais e outros colaboradores-chave para criar uma arquitetura comum e um espaço europeu para a educação superior. O Processo de Bolonha teve suas raízes em uma articulação estratégica entre as agendas nacionais e regionais. Após uma reunião em Paris em 1988 para celebrar o $800^{\circ}$ aniversário da Sorbonne, o ministro francês de Educação Claude Allegre obteve o acordo dos ministros de Educação da Alemanha, Itália e do Reino Unido para comprometer seus países com uma nova arquitetura para a educação superior (Ravinet, 2008). Essa arquitetura aprimoraria a Convenção para o Reconhecimento de Quaificações de Educação Superior na Região Europeia (Convenção de Lisboa), que tinha sido assinada em 1997. Allegre defendeu que, para desenvolver uma economia baseada no conhecimento, a Europa precisava tanto emular o sistema dos Estados Unidos quanto conter o fluxo de diplomados europeus para os Estados Unidos.

No ano seguinte, a Declaração de Bolonha (1999) comprometeu 29 países signatários com seis "linhas de ação” voltadas para estabelecer um Espaço Europeu de Educação Superior (EHEA em inglês), a ser realizado até 2010. Dentro desse “Espaço”, a mobilidade de docentes e discentes deveria ser reforçada com o alinhamento da garantia de qualidade nacional; uma estrutura compatível para a formação acadêmica seria desenvolvida com base no modelo 3+2+3 (licenciatura, mestrado e doutorado), a adoção de um sistema de transferência de créditos, e uma maneira comum de descrever as qualificações a serem delineadas estariam em um "suplemento ao diploma” pessoal. Em conjunto, esses mecanismos regulatórios eram vistos como capacitando o processo de Bolonha a atuar como veículo para aumentar a atratividade da Europa como mercado de educação para o mundo inteiro (Zgaga, 2006, p. 10).

O Processo de Bolonha é um acordo internacional voluntário, situado fora do quadro de governança da União Europeia, apesar de ser em grande parte impulsionado por interesses dela, e promove diversas iniciativas (como o sistema de transferência de créditos ECTS) originalmente pilotadas pela Comissão Europeia (Keeling, 2006). “Convencidos de que o estabelecimento do Espaço Europeu de Educação Superior exigia constante apoio, supervisão e adaptação às necessidades em constante evolução" (Bolonha Declaration, 1999), os ministros europeus de Educação decidiram reunir-se regularmente para avaliar o progresso, transformando o compromisso de Bolonha num processo político contínuo. O Grupo de Bolonha para Follow-Up (ou seja, Acompanhamento) tem a responsabilidade de fazer avançar esta pauta política contínua.

O número de sócios do Processo de Bolonha e do Espaço Europeu de Educação Superior tem crescido, passando a incluir, em 2009, 46 países com cerca de 5.600 instituições públicas e privadas com mais de 
16 milhões de alunos. O Espaço Europeu de Educação Superior inclui a Rússia e o sudeste da Europa; estende-se, assim, para muito além da UE como uma entidade constitucional.

A determinação da base de adesão ao Processo de Bolonha, no entanto, é um projeto geoestratégico importante. Como Hartmann (2008) aponta, inicialmente a adesão ao Processo de Bolonha foi baseada largamente nos signatários da Convenção de Lisboa (1997). Por razões históricas, isso incluía os Estados Unidos, o Canadá e a Austrália, através da definição da Europa por parte da Organização das Nações Unidas para a Educação, a Ciência e a Cultura (UNESCO) os Estados Unidos e o Canadá assinaram em 1975 e a Austrália, em 1986 (Hartmann, 2008, p. 213). Isso significou que esses países, sobretudo os Estados Unidos, tiveram direito de contribuir com propostas na elaboração inicial do Processo de Bolonha. Reconhecendo que a adesão teria de ser mais do que a Europa e os países candidatos à adesão (na medida em que era necessário incluir a Rússia, mas não seu concorrente, os Estados Unidos), algumas manobras políticas habilidosas eram necessárias. A Convenção de Lisboa, como base para a adesão formal ao Processo de Bolonha, foi descartada em 2003 em favor da Convenção Cultural Europeia do Conselho da Europa, excluindo assim os Estados Unidos, o Canadá e a Austrália. Hartmann (2008, p. 214) argumenta que essa foi uma de uma série de jogadas por parte da Europa para desafiar o papel imperial dos Estados Unidos na definição das normas, tornando esse país simultaneamente um rival, assim como um modelo.

\section{O "extrarregional" no projeto de educação superior da Europa}

Se a educação superior até então tinha sido orientada para a gestão do projeto territorial e sua política dentro da crescente região como resultado das adesões, a partir de 2003 os diversos aparatos políticos da Europa, em particular a CE, começaram a seguir uma estratégia extrarregional mais explícita de globalização que já tem efeitos tanto diretos quanto indiretos (Robertson, 2009a). Os efeitos diretos foram os resultados, tanto dentro quanto fora da Europa, das estratégias explícitas para realizar um espaço e um mercado europeu de educação superior competitivo, tais como o programa Erasmus Mundus, a Política de Vizinhança, as negociações do Acordo Geral sobre Serviços (GATS) da Organização Mundial do Comércio (OMC), a mobilização de antigos laços coloniais para alinhar estes com os interesses de mercado da Europa e assim por diante. Os efeitos indiretos foram as consequências das reações a essa estratégia nas economias-chave nacionais da economia global, onde o Processo de Bolonha passou a ser visto como uma ameaça em potencial (nos Estados Unidos, na Austrália), um modelo para a reestruturação interna (no Brasil, na China) ou a base para novos projetos regionais no mundo inteiro (na África, na América Latina).

O pretexto para essa mudança de estratégia remonta a 2003 e a maior conscientização, no âmbito da Comissão Europeia, sobre o declínio do crescimento no setor de serviços na Europa. Essa conscientização está encapsulada numa afirmação de Viviane Reding, membro da Comissão Europeia responsável pela Educação e Cultura, quando ela esboçou a base para “Tornar a UE uma figura proeminente no Mercado Mundial da Educação". Reding afirmou que "os governos nacionais sozinhos não podem enfrentar os desafios da globalização, das novas tecnologias e do mercado único” (2003, p. 2). Para a Comissão Europeia, isso significava trazer o setor privado para participar de suas diversas atividades, fazer avançar a liderança a nível europeu e continuar a promover a liberalização de serviços de educação pelo GATS da OMC.

Uma série de iniciativas de educação superior foi em seguida lançada pela comissão, todas caracterizadas por forte ênfase na competitividade global. A estas foram dadas força, foco e legitimidade na sequência da Revisão de Meio-Termo da Estratégia de Lisboa, presidida por Wim Kok (European Commission, 2005a). Kok (2004) argumentou que a Estratégia Lisboa 2010 tinha falhado em atingir um desempenho econômico satisfatório e que a Europa estava longe de cumprir 
as melhorias socioeconômicas que a Estratégia de Lisboa havia prometido. Kok anunciou que a Europa estava ficando rapidamente para trás de ambos, dos Estados Unidos e da Ásia. O espectro da China e da Índia, tanto como ameaça quanto oportunidade (Kok, 2004, p. 12), foi agora acrescentado como uma nova dimensão crítica aos desafios externos da Europa. Para a Europa competir, Kok argumentou, ela precisava “desenvolver a sua própria área de especializações, excelência e vantagem comparativa que, inevitavelmente, deve basear-se em um compromisso com a economia do conhecimento no seu sentido mais amplo" (Kok, 2004, p.12).

As Conclusões da Presidência do Conselho Europeu, por sua vez, reconheceram os variados resultados de Lisboa e demandaram ações urgentes, endossando a proposta da comissão para uma "nova" Estratégia de Lisboa (European Commission, 2005a, p. 3) que redirecionasse a atenção quase inteiramente para “empregos e crescimento". A Revisão de MeioTermo de Lisboa permitiu que a Comissão Europeia desse ênfase ao discurso de crise e o explorasse para assim alavancar uma variedade de novas iniciativas que não só demandavam uma reforma do setor de educação superior (European Commission, 2006), como também dirigiam a atenção da política quase inteiramente para investimento, inovação e emprego (European Commission, 2005a, p. 4; Collignon, 2006) (Figura 1).

Figura 1: Projetos e processos na construção da economia do conhecimento da Europa por meio da educação superior

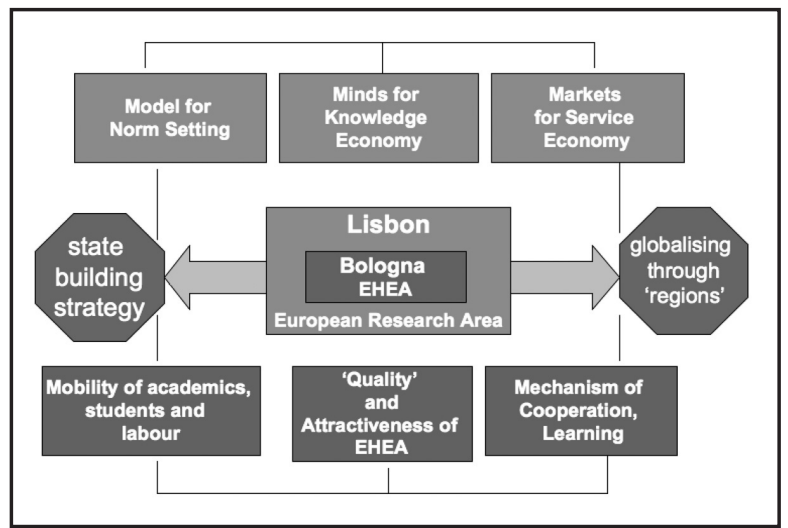

A “nova estratégia de Lisboa” - ao promover "menos, do mesmo" (Collignon, 2006) - abraçou firmemente uma visão neoliberal de como a economia do conhecimento europeia poderia ser melhorada, onde a educação superior era representada como um ponto crítico. A Comissão Europeia (2005b, 2006) considerou o papel das universidades na produção de uma economia do conhecimento europeia como derivado e dependente de sua relação com a indústria (daí a preocupação crescente com a "transferência de conhecimento”). O funcionamento das universidades, suas estruturas de governança e de incentivos, e não apenas seus produtos educacionais e de pesquisa, tornaram-se uma matéria de preocupação da política em nível europeu.

Uma semana após a reunião de março de 2005 do Conselho Europeu, o presidente da Comissão Europeia, José Manuel Durão Barroso, fez um discurso provocativo para o setor de educação superior na convenção da Associação da Universidade Europeia em Glasgow, intitulado "Universidades Fortes para a Europa” (Barroso, 2005), em que argumentou que o estado da educação na Europa, em comparação com outras regiões do mundo, não era nada menos do que “miserável” (p. 25). Tomando o novo rumo, a comissão começou a fazer recomendações diretas sobre a necessidade de "modernizar" as estruturas de governança, financiamento e gestão de pesquisa das universidades (incluindo medições de desempenho e incentivos), no intuito de capacitar a Europa para a competição mundial por mentes e mercados (European Commission, 2005b, 2006). Isso incluiu inserir os chamados "Países Terceiros" nos acordos de cooperação, para estancar os seus fluxos para os Estados Unidos. A educação tornou-se, assim, importante espaço de “diálogo setorial” com uma certa quantidade de países asiáticos, incluindo a China. O programa Erasmus Mundus de intercâmbio global, lançado em 2003 com um orçamento de 230 milhões de euros para os seus quatro primeiros anos, incluiu financiamento suplementar para aumentar a participação de estudantes internacionais oriundos de países asiáticos específicos, incluindo Índia e China 
(os chamados “Janelas Asiáticas”). O Erasmus Mundus destinou-se a incentivar estudantes talentosos a estudar e permanecer na Europa após os seus estudos para contribuir para a competitividade econômica do continente. Até 2008, o programa apoiou mais de 100 cursos de mestrado.

A estratégia da UE de captar talento global também procurou atrair os pesquisadores líderes europeus de volta para a Europa com o aprimoramento da política de "Marie Curie” e dos instrumentos do programa. No programa Quadro 7 da UE para o período 2007-2013, voltado para o financiamento de pesquisa, a dimensão internacional foi reforçada, com recursos financeiros orientados para a "volta e reintegração" dos pesquisadores líderes que trabalham no estrangeiro. Além disso, os estudantes que já tinham estudado na Europa durante pelo menos quatro dos cinco anos anteriores tornaram-se elegíveis para solicitar fundos como bolsista da Marie Curie para continuar as pesquisas nas universidades europeias. A comissão, contra muita resistência inicial, também elaborou uma proposta para um Instituto Europeu de Tecnologia, para "atuar como polo de atração para os melhores cérebros, ideias e empresas de todos os continentes" (European Commission, 2005b). Uma versão reduzida do original foi lançada em 2008 (Jones, 2008). A educação superior, assim, vem se tornando profundamente incorporada aos esforços da UE para melhorar a sua posição econômica e influência no mundo.

Crucial para esse processo foi o notável desdobramento (embora incorporado desigualmente) do Processo de Bolonha e dos seus diversos instrumentos; o Tuning Programme ${ }^{1}$ (iniciado em 2003) para traduzir disciplinas de estudo em competências e a criação de um Registro Europeu de Qualificações (implantado em 2008) para assegurar a garantia da qualidade dos prestadores de serviços de educação superior, são cocons-

${ }^{1}$ N.T.: Manteremos no texto a expressão Tuning Programme, que significa Programa de Afinamento. Essa opção é coerente com outros programas já referidos no texto, como Erasmus, Erasmus Mundus, Tempus etc. titutivos de novos objetos e assuntos da governança. O uso combinado desses instrumentos também provocou muita discussão nas economias-chave ao redor do mundo sobre as implicações desse projeto político de regulação sobre os seus interesses nacionais e suas estratégias de longo prazo. Essa discussão é suscetível de ser alimentada pela recente convocação para licitações, por parte da Comissão Europeia, para desenvolver um sistema de classificação que poderia ser aplicado em nível mundial (Robertson, 2009b). A intenção é desafiar o domínio dos sistemas de ranqueamento da Shanghai Jiao Tong e do Times Higher Education Supplement em relação aos interesses europeus, em grande medida porque, como argumentado especialmente pelos Estados-membros continentais (sobretudo a França), tais sistemas de ranqueamento combinam com e consolidam os interesses dos Estados Unidos.

Em suma, é evidente que as técnicas de governança regional têm a sua potência, não só em termos de regulação interna, mas têm sido cada vez mais vistas como tendo potencial para desafiar a liderança da base normativa no setor dos serviços de educação. A ele foi dado um impulso considerável pelos efeitos diretos e indiretos do projeto europeu de educação superior em outras economias nacionais e em ambições regionais nascentes em região próxima e para além.

Em um comunicado da CE em 2006, a comissão alegou que "Os ministros veem o Espaço Europeu de Educação Superior como um parceiro dos sistemas de educação superior em outras regiões do mundo" e observou que

\footnotetext{
[...] o papel e a visibilidade da educação superior no âmbito das relações externas da UE são cada vez mais orientadas para: os países vizinhos, onde programas como o Tempus tenha sido investido com um mandato explícito do Processo de Bolonha (Política Europeia de Vizinhança); nações industrializadas (OCDE/G8) e países em desenvolvimento (Alba, Asia Link etc.). (p. 7)
}

Ao Bologna Follow-up Group (BFUG) também foi dada a incumbência de elaborar e pactuar uma estratégia para a dimensão externa, a fim de fortalecer a 
atratividade do Espaço Europeu de Educação Superior (BFUG Work Program, 2005-2007; Zgaga, 2006). Essa estratégia, ou seja, estar com outras regiões, em vez de países (BFUG, 2005, grifo nosso), foi incluída na pauta da reunião dos ministros realizada em Londres em 2007. Isso significa desenvolver as regiões de interesse prioritário para a Europa. A tarefa à frente é criar as condições para a mobilidade internacional (modo 4 do Acordo GATS), as estruturas de reconhecimento, a cooperação e a capacidade de atração.

No entanto, muitos dos pesquisadores europeus que a União Europeia tentava atrair de volta estavam baseados nos Estados Unidos, país bem estabelecido como principal destino internacional para estudantes e pesquisadores estrangeiros. Os Estados Unidos também abrigam muitas das universidades de ponta do mundo, dominando os rankings mundiais desde a década de 1950 (Graham \& Diamond, 1997; THES, 2008; Shanghai Jiao Tong, 2008). Segundo a maioria dos comentadores, “um gradiente de desempenho” continua a separar as universidades de pesquisas dos Estados Unidos de todas as outras (Herbst, 2004). No entanto, análises nos Estados Unidos revelam que outros países estavam recuperando rapidamente o atraso em várias frentes (OCDE, 2006; THES, 2006; Spellings Commission, 2006) e que "existem indicadores preocupantes de estagnação e declínio real” (Douglass, 2006) no setor de educação superior dos Estados Unidos.

Em algumas arenas dos Estados Unidos, há interesse agudo no desenvolvimento na Europa. A admiração é também expressa pela rapidez das mudanças europeias e da força de vontade política que as apoia (Jaschik, 2006). A American Association of International Educators (NAFSA) também criou uma Taskforce² sobre o Processo de Bolonha e há interesse crescente, em nível institucional, sobre as novas credenciais e modelos de Bolonha. Porém, até agora o efeito das reformas de Bolonha sobre os Estados Unidos tem sido impulsionar o debate em torno de uma crise na educação superior dos Estados Unidos e a necessidade de revisar o marke-

${ }^{2}$ N.T.: Grupo de trabalho chamado força-tarefa, criado para realizar missão específica. ting, os processos de obtenção de vistos e de admissão para conter o declínio na participação do mercado de exportação de educação superior (Robertson \& Keeling, 2008).

Isso contrasta fortemente com a perspectiva australiana, que vê a conquista de dominância no mercado mais claramente como um jogo de números, uma disputa por mais estudantes. Em abril de 2006, Julie Bishop, a então ministra australiana de Educação, Ciência e Treinamento, apresentou uma proposta intitulada "O Processo de Bolonha e a Austrália: os próximos passos”. Essa resposta oficial ao Processo de Bolonha alegou que a Austrália deverá garantir a compatibilidade com o Processo de Bolonha ou enfrentar os riscos associados em ser um "forasteiro em relação ao processo de Bolonha” (Bishop, 2006). Vistos dessa forma, os desenvolvimentos da educação superior europeia representam grande ameaça por vários motivos. Há um fluxo constante de estudantes da Europa; sendo compatível com o Processo de Bolonha, permite e reforça esses movimentos, uma vez que os estudantes sairiam de uma universidade australiana com uma qualificação que é aceitável no mercado de trabalho europeu. Em segundo lugar, o governo australiano está bem ciente de que a Comissão Europeia tem usado uma série de instrumentos para criar intercâmbios e parcerias nas regiões da Ásia e da América Latina (Robertson, 2009a) a fim de fazer avançar os interesses econômicos da UE. Se a Europa se tornasse um destino desejável para estudantes asiáticos por causa de sua estrutura de taxas competitivas, do status das universidades e da tendência crescente para ensinar em inglês nos cursos de pós-graduação, então a Europa pode também ameaçar a posição dominante da Austrália nesse mercado.

Em relação à região da Ásia - região de preocupação mais estratégica para a Austrália - a Comissão Europeia tem usado o programa Erasmus Mundus “Janelas Asiáticas” para recrutar estudantes indianos e chineses para cursar mestrados em universidades europeias. O Processo de Bolonha tem também sido o principal tema de conversa numa série de reuniões Ásia-Europa desde 2005. Somado a isso, alguns paí- 
ses asiáticos vêm acompanhando de perto o Processo de Bolonha, enquanto a China procurou o status de observador na reunião de ministros da UE de 2007. Em abril de 2007, a Austrália assinou uma declaração conjunta com a UE para tornar-se compatível com o Processo de Bolonha e reforçar a cooperação para abranger questões de garantia de qualidade, benchmarking e indicadores e quadros de qualificações (Figel \& Bishop, 2007). Seus programas são vistos pelo governo federal australiano como sendo cruciais para o desenvolvimento do novo trabalhador e cidadão australiano que "tem consciência global".

O Processo de Bolonha e a criação do Espaço Europeu de Educação Superior claramente inspiraram formas mais estratégicas de pensar sobre as regiões e o valor de criar e institucionalizar o papel da educação nas relações regionais. Enquanto a educação tem estado na ordem do dia em fóruns como a Asia-Pacific Economic Cooperation (APEC) (Dale \& Robertson, 2002), o Processo de Bolonha oferece um tipo diferente de imaginário, criando uma arquitetura regional de educação superior que traz a possibilidade de um mercado único para os serviços de educação superior e o potencial de melhorar a empregabilidade no futuro. Esses desenvolvimentos sugerem que as economias nacionais, como as da Austrália e dos Estados Unidos, estão envolvidas num complexo conjunto de posicionamentos estratégicos a fim de gerir a ameaça (e as oportunidades) colocada pelo rápido crescimento do Espaço Europeu de Educação Superior e o Processo de Bolonha. A entrada da UE nesse domínio claramente "deslocou” o equilíbrio do terreno num sentido muito diferente. Tudo indica que não é possível ignorar essas pressões - considerando as múltiplas formas como a UE vem se envolvendo em projetos inter-regionais, tanto em regiões da Ásia quanto da América Latina (Robertson, 2006, 2008a, 2009a; Robertson \& Keeling, 2008; Zgaga, 2006), e a longa sombra jogada pela China. Ao mesmo tempo, as economias, como a do Brasil, estão usando a arquitetura de Bolonha como um modelo para a racionalização de acesso, a fim de gerar ganhos de eficiência do novo sistema. Esses desenvolvimentos oferecem claramente aos brasileiros diplomados uma articulação eficiente com os mercados europeus de pós-graduação e de trabalho num futuro próximo, provendo uma alternativa viável para os Estados Unidos como destino para estudos e emprego.

\section{"Capacidades" e "pontos de viragem" na educação superior global}

Esta análise mostra que estamos lidando com um conjunto altamente complexo e interligado de processos e relações. Em todos esses espaços geopolíticos, a educação superior tem sido considerada um "motor crítico” para a competitividade nacional e regional na economia global, e uma batalha global por mentes e mercados já começou para apoiar isso. É evidente que esses setores nacionais e regionais de educação superior se tornaram mais estreitamente interligados no sistema global, embora, como temos demonstrado, a natureza e a consequência dessas relações variem em função das suas diferentes histórias, tamanho e forma das suas economias, dos interesses geopolíticos, dos arranjos políticos internos, da natureza específica do setor de educação superior, dos tipos de estratégias de desenvolvimento que são implantados e assim por diante.

Tenho explorado as estratégias de territorialização da União Europeia na educação superior, observando como a UE cooptou primeiramente a educação superior como parte de seu projeto regional e, em seguida, exportou as reformas de Bolonha para alargar sua "esfera de influência" sobre outras partes do mundo. O êxito da UE em programas educativos fornece inicialmente um conjunto rico de experiências, relações, recursos e discussões como base para a formulação de novas políticas. O relançamento da Agenda de Lisboa de competitividade deu a essas elaborações de "baixo registro” uma tração política, fornecendo o mandato e a filosofia política para alcançar mais progresso, enquanto o Processo de Bolonha forneceu uma gama de ferramentas úteis. A UE está agora buscando duas estratégias de internacionalização complementares: em primeiro lugar, tentar fazer dominante seu modelo de 
educação superior, a fim de aumentar a sua participação no mercado global de educação superior internacional; em segundo lugar, tentar aproveitar mais das melhores mentes do mundo para impulsionar a economia europeia. Ambos os objetivos colidem diretamente com os interesses estabelecidos em países como a Austrália e os Estados Unidos na educação superior.

Os Estados Unidos continuam a dominar o mercado internacional de estudantes, sendo seu principal interesse atrair, desenvolver e reter talentos para suas pesquisas e outras atividades econômicas. O emprego das melhores "mentes” do mundo para produzir inovação e gerar valor para a economia estadunidense é central para a estratégia dos Estados Unidos em relação à economia do conhecimento. No entanto, a administração dos Estados Unidos também está consciente da maneira pela qual a educação superior - concebida em termos diplomáticos e como uma força civilizadora - pode ser utilizada para mediar a lacuna de credibilidade na política externa que se abriu em função das suas políticas de segurança da pátria (“homeland security”) e da "guerra contra o terror”. A concretização rápida do Espaço Europeu de Educação Superior tem proporcionado uma alavanca útil para esse debate interno.

Em contrapartida, desde a década de 1990, a Austrália tem perseguido de forma vigorosa uma política para construção do setor de educação superior como um mercado e exportar a educação globalmente. Ela conseguiu assegurar uma posição competitiva nesse mercado em um contexto em que muitos países asiáticos estavam procurando investir na educação superior, mas tinham capacidade limitada para provêla eles mesmos. A Austrália foi, portanto, capaz de aproveitar a sua localização regional para avançar e tornou-se o maior fornecedor de serviços de educação na região, e suas instituições de educação superior já se tornaram altamente dependentes do fluxo de receitas que essa política gerou. Para os Estados Unidos e a Austrália, há muito em jogo para as suas economias (do conhecimento).

A pergunta a ser feita, no entanto, é: por que agora? Considerando que ambos - o Processo de
Bolonha e a Agenda de Lisboa - são projetos em vigência desde o início da década, por que a Austrália e os Estados Unidos responderam de diferentes formas, neste momento em particular? Nós acreditamos que há uma série de razões interligadas para isso. A combinação do relançamento da Agenda de Lisboa 2005, da implantação de estratégias globalmente orientadas que desafiam os interesses regionais dos Estados Unidos e da Austrália, juntamente com os surpreendentes resultados e o tamanho do Espaço Europeu de Educação Superior, representam uma nova "capacidade” material e que, quando adicionada à dinâmica endógena em ambos (Estados Unidos e Austrália), um “ponto de viragem” crítico já foi atingido e está levando a uma integração mais compacta da economia do conhecimento global.

Adotamos aqui as definições de "capacidade" e "tipping point" (ponto de viragem) de Saskia Sassen (2006) para falar sobre como as mudanças que criam novos caminhos ocorrem e como novas articulações do ambiente de educação superior vêm se configurando. Para Sassen, a “capacidade” e os "pontos de viragem” são dois elementos-chave que permitem analisar as transformações fundamentais em sistemas complexos ao longo do tempo.

“Capacidades" são definidas por Sassen como:

\section{[...] produções coletivas para as quais o desenvolvimento envolve tempo, confecção, competição e conflitos, e cujas utilidades são, em princípio, multivalentes, porque são condi- cionadas pelo caráter dos sistemas relacionais dento dos quais elas funcionam. Ou seja, uma determinada capacidade pode contribuir para a formação de um sistema relacional muito diferente daquele no qual tem a sua origem. (2006, p. 7-8)}

Há vários pontos a notar: em primeiro lugar, que as capacidades são produzidas através de processos discursivos e materiais, como vemos, por exemplo, com a produção da "Europa”, a produção do Espaço Europeu de Educação Superior, a produção de uma América do Norte competitiva e assim por diante. Elas são, então, projetos políticos. Em segundo lugar, a produção de capacidades envolve atores e institui- 
ções lutando por ideias, recursos, embutindo poder nas instituições e assim por diante. Esses processos são dinâmicos, contingentes e incompletos. Como resultado, eles são fluidos. Em terceiro lugar, que o poder é relacional; uma capacidade tem que ser vista por outros - como, no nosso caso, os Estados Unidos ou a Austrália - como tendo certa força ou um conjunto possível de resultados - mesmo que essa capacidade seja amplificada na imaginação dos outros e usada para propósitos que não foram previstos, como mudanças endógenas. Seu poder deriva do fato de que pode ter efeitos em outros sistemas. Em quarto lugar, as capacidades podem incluir recursos tecnológicos, organizacionais e naturais e, como tal, são concentrações de poder material e discursivo (Cox, 1996, p. 98). Finalmente, uma determinada capacidade pode contribuir para a formação de um sistema relacional muito diferente daquele no qual se originou. Sassen defende que as instituições de Bretton Woods - o Fundo Monetário Internacional (FMI), o Banco Mundial, mais tarde a OMC - chegaram a ter um tipo particular de capacidade global a partir da década de 1970, com o colapso do acordo de pós-guerra e a desnacionalização dos Estados. Da mesma forma, poderíamos argumentar que o projeto de regionalização da UE está agora contribuindo para a formação de um sistema relacional muito diferente, que é ao mesmo tempo mais global e está transformando as lógicas nacionais em outras partes do mundo.

A produção coletiva de uma Europa mais voltada para o exterior e globalmente competitiva pelas elites europeias tem consideravelmente mais força material do que a perspectiva privilegiada que gente de casa pode lhe conceder. Grande parte da capacidade do projeto europeu é derivada de sua aparência externa de coerência (ou pelo menos a coerência que lhe é atribuída por analistas externos). Assim, a capacidade da União Europeia é, em certa medida, ilusória. É ainda uma questão em aberto saber se a UE será capaz de orientar as políticas e fundos suficientes para habilitála a se tornar uma marca concorrente e uma ameaça substancial para as outras regiões. Um levantamento internacional de "percepções de estudantes” (ACA, 2005) mostra que o branding com a marca da educação superior europeia não foi totalmente bem-sucedido. Enquanto o programa Erasmus Mundus pode fazer algumas incursões nesse sentido e os instrumentos do programa Marie Curie poderiam agir como uma atração suficiente para trazer acadêmicos de distinção de volta à Europa, as disjunções entre a economia europeia do conhecimento recentemente reimaginada e a economia real multifacetada e multiescalar da Europa limitarão necessariamente o impacto e a orientação da estratégia da Europa referente à educação superior/à economia do conhecimento (Robertson, 2008b). Existem lacunas consideráveis - de capacidade, habilidade e legitimidade - que prejudicam que a UE tenha um impacto global através de suas iniciativas de política de educação superior.

O dilema para países como a Austrália é o que fazer ante a nova capacidade europeia: ficar de fora do modelo de Bolonha ou localizar-se por dentro? Os Estados Unidos já foram capazes de usar a ameaça da capacidade da UE e da posição dos Estados Unidos na economia global para legitimar um discurso de crise sobre "responsabilidade" e "transparência”, no intuito de forçar uma agenda para mudanças nas universidades. A UE também vem usando, desde 2004, um discurso de crise para aprimorar sua capacidade ao colocar em movimento uma gama de iniciativas destinadas diretamente a reconfigurar o mandato e a governança da educação superior na Europa - incluindo a identificação e mobilização de recursos de um conjunto de instituições de elite de educação superior em toda a Europa (por exemplo, o projeto IET e o Conselho Europeu de Pesquisas).

Isso traz consigo um segundo elemento fundamental para a compreensão das mudanças globais: a ideia de tipping points ("pontos de viragem"). Sassen (2006, p. 7) refere-se a eles como:

\footnotetext{
[...] identificar a dinâmica envolvida na capacidade de mudança dos sistemas relacionais e/ou lógicas de organização. Isto é, este tipo de análise pode acomodar o fato da viragem, ou do evento, $[. .$.$] ao invés de ficar confinado a$
} 
um resultado. (p. 9)

Para identificar o tipping point, temos de olhar de perto a dinâmica, os mecanismos, o ato, o evento, os processos que estão envolvidos no deslocamento do registro de efeito, de tal forma que não há fácil retorno e uma nova lógica é posta em marcha ${ }^{3}$. É onde, em certas circunstâncias, elementos quantitativos são transformados em mudança qualitativa. Um foco nos tipping points identificaria as dinâmicas envolvidas que deslocaram ou trocaram a lógica do pós-guerra por outra. Em segundo lugar, tipping points estão claramente relacionados com a capacidade - mas a capacidade não é suficiente por si própria, como podemos ver com a Europa.

Assim, como esse conceito é útil para a minha análise? Poderíamos argumentar que o tipping point em direção a um conjunto mais integrado de educação superior global é composto pela seguinte dinâmica: uma Europa ampliada em função da adesão de novos países; a inserção de uma agenda neoliberal mais assertiva na Europa como resultado da Revisão de Meio-Termo de Lisboa; uma única arquitetura para a educação superior europeia, estruturada como um sistema diferenciado para a competitividade global; os interesses de globalização da Europa em busca de talentos globais, incluindo o regresso de pesquisadores à Europa; o enredamento das economias exportadoras (como a da Austrália) em várias regiões do mundo, incluindo a Europa; a emergência da China e da Índia como mercados e poderes em potencial; e os interesses estratégicos de todos os jogadores em ter uma participação na Europa; as políticas endógenas nos Estados Unidos, onde a economia do conhecimento da Europa é amplificada pelo seu "valor de provocar choque”, que, por sua vez, dá capacidade à Europa; e a dependência não-diminuída dos Estados Unidos

\footnotetext{
${ }^{3}$ Um exemplo que pode ser citado para ilustrar este ponto é o que Jessop (1999) argumenta ser a mudança do Estado Nacional de Bem-Estar keynesiano que caracterizou o acordo após a II Guerra Mundial ao Regime Pós-Nacional schumpeteriano a partir da década de 1990 .
}

do fluxo regular de diplomados oriundos da Europa bem como de outras partes do mundo. A reunião dos ministros europeus de Educação realizada em Londres em maio de 2007 vinculou esses fatores uns aos outros para criar um "momento político" crítico, quando os pontos de vista dos colaboradores e observadores foram formalmente articulados, as posições assumidas, e respostas políticas formuladas. Até março de 2009, o modelo de Bolonha já era visto como firmemente global, sendo convidados países ao redor do mundo (além dos signatários formais de Bolonha) para participar de reuniões importantes.

Quanto mais forte é o vínculo de uma nação com a economia global, mais ela vai se sentir pressionada a "saltar na trilha" da nova lógica que está sendo produzida. No entanto, essas trocas não são automáticas; são o resultado da competição e do conflito. No caso da Austrália, seu setor de educação superior está tão profundamente enredado nas economias regional e global que ele agora é confrontado com a realidade estratégica do momentum de mudar sua lógica interna - sua arquitetura relativamente mais flexível de educação superior - para acomodar uma realidade emergente da nova Europa competitiva. Não apenas os setores de educação superior nessas regiões estão se tornando mais integrados, mas também podemos ver surgindo nesses espaços regionais um mercado global altamente estratificado de educação superior. Uma "Ivy League"4 ou "Superliga” global (Markwell, 2006) de universidades é identificável, a qual já opera em um plano internacional e competitivo e que está se mantendo afastada das sugestões de novos modelos ou mercados que estão reconfigurando radicalmente suas operações, objetivos e perspectivas. Como Graham e Diamond (1997) observaram, no contexto estaduni-

${ }^{4}$ N.T.: Trata-se de um grupo de oito universidades privadas do Nordeste dos Estados Unidos da América. A Ivy League, também conhecida como “as oito antigas”, é constituída pelas instituições de maior prestígio científico nos Estados Unidos e no mundo e, como consequência, a denominação tem conotação de excelência acadêmica.(Ver www.admissionsconsultants.com/ college/ivy_league_table.asp.) 
dense o topo dessa hierarquia pode ser notavelmente estável. Embora tenha havido sistemas de educação superior com instituições de elite e intensa competição por status (Marginson, 2006, 2007), o que é diferente hoje - e por que isto importa mais - é a centralidade de tais sistemas altamente estratificados para a nova economia global. Essas instituições que desejam ficar de fora da lógica da viragem (tipping) estão proativamente mobilizando seus próprios recursos e capacidades a fim de gerar um circuito alternativo com sua própria “elite”/ vantagem competitiva. Eles estão rejeitando a lógica de compatibilidade, definindo os seus próprios caminhos na globalização e estendendo seu alcance escalar.

Uma última questão importante permanece em aberto: por que o BFUG, a Comissão Europeia, juntamente com os principais atores em nível europeu, como os Estados Unidos, todos comprometidos com o desenvolvimento da Europa como projeto político, têm procurado priorizar regiões em vez de países como um meio de promover o que Zgaga denomina “eco” global de Bolonha (2006, p. 16)? Em um nível podemos ler o foco em outras regiões como uma jogada política, capaz de invocar um tipo especial de legitimidade decorrente de ser signatário da Convenção de Lisboa (1997). Nas palavras da convenção, aproximar-se das demais regiões do mundo contribuirá para a capacidade da Europa de "promover paz, compreensão mútua e tolerância” (Zgaga, 2006, p. 19). No entanto, podemos também ler a priorização de parcerias regionais como estratégica; a consequência de lutas "sobre as geometrias cada vez mais variáveis de governança dentro e fora das fronteiras da União Europeia” (Jessop, 2005, p. 225). Parcerias regionais recorrem às capacidades dos antigos laços coloniais, da diáspora da sua elite e de redes intelectuais (por exemplo, a África francófona; a África lusófona; a América Latina). Elas também são mecanismos úteis para ativar e constituir novas formas de re/organização regional que atrairão e esboçarão a existência das estruturas normativas europeias (instrumentos de reestruturação europeia de educação superior) e poder normativo, em vez de sua alternativa: a capacidade estadunidense para elaborar normas (Hartmann, 2008).
No entanto, argumentaria também que a negociação através de regiões também significa ser capaz de pular escalas (Jessop, 2005, p. 226), contornando a ordem escalar estabelecida como as do Estadonação e sua pretensão westfaliana ao território e à soberania, procurando, em vez disso, progredir e institucionalizar seus interesses através de novas alianças. Como este trabalho tem argumentado, a redistribuição escalar da mão de obra do Estado e da educação é um aspecto importante da reestruturação econômica e política (Collinge, 1999). Vistos dessa forma, os inter-regionalismos oferecem uma plataforma para e a possibilidade de uma região nascente - neste caso Europa - agir à maneira de um Estado, reivindicando sua pretensão à dominância em uma arena inter-regional que opera como um terreno estrategicamente seletivo, dadas as características, capacidades e atividades das organizações localizadas nessa escala regional.

\section{Considerações finais}

Uma preocupação primordial deste trabalho foi demonstrar a natureza e as consequências dessa relação multiescalar e multicêntrica dentro e através de espaços - para mover o nosso foco de análise de explicações bilaterias causais ou da atenção mais recente sobre o posicionamento e a tomada de posição. Essas explicações oferecem informações úteis, porém não nos dão uma pegada analítica suficiente sobre as transformações que estão ocorrendo dentro e através dos espaços estatais que, por sua vez, alteram as lógicas e dinâmicas que formam as trajetórias de desenvolvimento. Em outras palavras, estou olhando para o “não-tão-óbvio" bem como para resultados mais óbvios da globalização; os processos de desnacionalização dentro do domínio nacional, bem como o mais visível reescalamento a nível global que estão ocorrendo. Tenho analisado como as lógicas internas de competitividade em nível regional estão começando a transformar o campo de negócios globalmente. Embora esteja bem no início do processo, não deixa de ser possível ver um conjunto de dinâmicas em jogo, em que novas capacidades estão surgindo 
para perturbar - e reconfigurar - o equilíbrio de poder. Um conjunto inteiro de novas regras do jogo está emergindo, em que poder e influência nesse sistema global mais integrado e estratificado estão sendo radicalmente reformados, e não simplesmente realocados.

Há novos elementos nessa mistura que eu não abordei neste trabalho, embora sejam claramente importantes: a ascensão da China e o significado das suas próprias reformas de educação superior; o compromisso de Cingapura para se tornar um provedor regional de serviços de educação; a criação dos "polos" de educação superior na região árabe; a Área Alternativa das Américas; a posição ambivalente e ambígua do Reino Unido nas negociações de Bolonha e assim por diante. Também não prestei atenção suficiente para as estratégias de cobertura de apostas nos dois lados de muitas das instituições de educação superior e das suas redes de influência em diversos níveis da hierarquia mundial, em relação às limitações que uma arquitetura semelhante àquela de Bolonha possa impor às suas instituições. Uma análise mais aprofundada desses fatores seria ricamente recompensadora. Separadamente e em conjunto, tais desenvolvimentos, juntamente com aqueles que apresentamos antes, estão transformando espaços globais, regionais e nacionais, as inter-relações entre eles, bem como o papel e a importância das universidades dentro deles.

\section{Referências bibliográficas}

ACA - Academic Cooperation Association. Perceptions of European higher education in third countries, Outcomes of a study by the Academic Cooperation Association. Brussels: ACA, 2005. BARROSO, José M. B. Strong Universities for Europe. Speech given to the European Universities Association Convention, Glasgow, $2^{\text {nd }}$ april 2005.

BFUG. From Berlin to Bergen: General Report of the Bologna Followup Group to the Conference of European Ministers Responsible for Higher Education. Bergen, 19-20 may 2005. Oslo, 3 may 2005.

BIELER, Andreas; MORTON, Adam (Eds.). Social forces in the making of the new Europe: the restructuring of European social relations in the global political economy. Basingstoke: Palgrave Macmillan. 2001.
BISHOP, Julie. The Bologna Process and Australia: next steps. Canberra: Australian Federal Department of Education, Skills and Training, 2006.

BOLOGNA DECLARATION. The European Higher Education Area. Joint Declaration of the European Ministers of Education Convened in Bologna at the 19th june, 1999.

COLLIGNON, Stefab. The Lisbon Strategy, macroeconomic stability and the dilemma of governance with governments. Boston/London: Harvard University and London School of Economics, 2006.

COLLINGE, Chris. Self-organisation of society by scale: a spatial reworking of regulation theory. Environment and Planning D: Society and Space, 17. 5, p. 557-574. 1999.

CORBETT, Anne. Universities and the Europe of knowledge: ideas, institutions and policy entrepreneurship in European Community higher education policy, 1955-2005. Basingstoke: Palgrave Macmillan, 2005.

COX, Robert. Approaches to world order. Cambridge: Cambridge University Press, 1996.

DALE, Roger; ROBERTSON, Susan. Regional organisations as subjects of globalisation. Comparative Education Review, v. 46, n. 1, p.10-36, 2002.

DOUGLASS, John A. A. The Waning of America's Higher Education Advantage: International Competitors are No Longer Number Two and Have Big Plans in the Global Economy. Research and Occasional Paper Series, Center for Studies in Higher Education, University of California, Berkeley, n. 9, 2006.

EUROPEAN COMMISSION. Communication to the Spring European Council. Working Together for Growth and Jobs. A New Start for the Lisbon Strategy. COM 2005a.

Mobilising the brainpower of Europe: enabling universities to make their full contribution to the Lisbon Strategy. COM (2005) 152 final. 20 $0^{\text {th }}$ april, 2005b.

. Delivering on the modernisation agenda for universities: education, research and innovation. COM (2006) 208 final. $10^{\text {th }}$ may, 2006.

FERRERO-WALDNER, B. Governance, education and European Integration. Speech/05/74. Introductory Speech by the European Commissioner for External Relations to the Conference of the Graz Process, Graz, 28 january, 2005.

FIGEL, Jan; BISHOP, Julie. Joint Declaration between the European Union and Australia. European Commission and the Government of Australia wish to reinforce co-operation in the fields of education and training. Brussels: European Commission, 2007. 
GRAHAM, Hugh D.; DIAMOND, Nancy. The Rise of American Research Universities: Elites and Challengers in the Postwar Era. Baltimore: Johns Hopkins University Press, 1997.

HARTMANN, Eva. Bologna goes global: a new imperialism in the making, Globalisation, Societies and Education, v. 6, n. 3, p. 207-220, 2008.

HERBST, Marcel. The Production-Morphology Nexus of Research Universities: The Atlantic Split. Higher Education Policy, n. 17, p. 5-21, 2004.

HINGEL, Anders J. Education policies and European governance: contribution to the inter-service groups on European governance. Brussels: European Commission, Directorate-General for Education and Culture; European Journal for Education Law and Policy, n. 5, p. 7-16, 2001.

HUISMAN, Jeroen; WENDE, Marijk van der. The EU and Bologna: are supra- and international initiatives threatening domestic agendas? European Journal of Education, v. 39, n. 3, p. 349-357, 2004.

JASCHIK, Scott. Making Sense of "Bologna Degrees". Inside Higher Education. $6^{\text {th }}$ november 2006. Disponível em: <http:// insidehighered.com/news/2006/11/06/bologna>.

JESSOP, Bob. The changing governance of welfare: recent trends in its primary functions, scale and modes of coordination. Social Policy and Administration, v. 343, n. 4, p. 348-359, 1999.

. The political economy of scale and European governance. Tijdschrift voor Economische en Sociale Geografie, v. 96, n. 2, p. 225-230, 2005.

JONES, Peter. The European Institute of Technology and the Europe of Knowledge: A Research Agenda. Globalisation, Societies and Education, v. 6, n. 3, p. 291-308, 2008.

KEELING, Ruth. The Bologna Process and the Lisbon research agenda: the European Commission's expanding role in higher education discourse. European Journal of Education, v. 41, n. 2, p. 203-223, 2006.

KOK, Wim. Facing the Challenge Ahead: The Lisbon Strategy for Growth and Employment, Report from the High Level Group. Brussels: European Commission, 2004.

MARKWELL, Don. Issues in Global Higher Education. Speech by the Warden of Trinity College, University of Melbourne, at a seminar on The Future of Universities, University of Queensland, St Lucia, $19^{\text {th }}$ august, 2006.

MARGINSON, S. Dynamics of national and global competition in higher education. Higher Education, n. 52, p. 1-39, 2006.
Global position and position-taking: The case of

Australia. Journal of Studies in International Education, v. 11, n. 1, p. 5-32, 2007.

OCDE. Internationalisation and Trade in Higher Education: Opportunities and Challenges. Paris: OCDE, 2004.

. Education at a Glance 2006. OCDE Briefing Note for the United States, 2006.

QUINTIN, Odile. Speech by the European Commission's DirectorGeneral for Education and Culture to the European University Institute's Post-Doctoral Training Programme in the Social Sciences, 4 october 2006.

RAVINET, Pauline. From Voluntary Participation to Monitored Coordination: why European countries feel increasingly bound by their commitment to the Bologna Process. European Journal of Education, v. 43, n. 3, p. 353-367, 2008.

REDING, Viviane. We need to implement wholeheartedly the Bologna Process, Speech to the Berlin Conference on Higher Education, Berlin, SPEECH/03/418, 18 $8^{\text {th }}$ September, 2003.

ROBERTSON, Susan. The politics of constructing (a Competitive) Europe(an) through internationalising Higher Education: Strategy, Structures, Subjects. Perspectives in Education, v. 24, n. 4, p. 2944, 2006.

. Embracing the global: crisis and the creation of a new semiotic order to secure Europe's knowledge-based Economy. In: FAIRCLOUGH, N.; WODAK, R.; JESSOP, B. (Eds.). Education and the Knowledge-based Economy in Europe. Netherlands: Sense Publications, 2008a.

"Europe/Asia” regionalism, higher education and the production of world order. Policy Futures in Education, v. 6, n. 6, p. 718-729, 2008b.

The EU, Regulatory State Regionalism, and Higher

Education. Paper presented to the International Studies Association Annual Conference, February 15-18 ${ }^{\text {th }}$, New York, 2009a.

“Rankings": European Higher Education, League Tables and World Re-orderings. Paper presented to the ESRC Seminar Series, “Changing Cultures of Competitivism”, University of Bristol, 23 ${ }^{\text {rd }}$ January, 2009b.

.; KEELING, R. Stirring the Lions: Strategy and

Tactics in Global Higher Education. Globalisation, Societies and Education, v. 6, n. 3, p. 221-240, 2008.

SASSEN, Saskia. Territory, authority, rights: from medieval to global assemblages. Princeton: Princeton University Press, 2006. 
SHANGHAI JIAO TONG. World University Rankings. 2008. Disponível em: <http://www.arwu.org>. Acesso em: 28 fev. 2009.

SPELLINGS COMMISSION. A Test of Leadership: Charting the Future of U.S. Higher Education (September). A Report of the Commission Appointed by U. S. Secretary of Education Margaret Spellings, 2006.

TEICHLER, Ulrich; KEHM, Barbara M. Towards a New Understanding of the Relationships between Higher Education and Employment (1995). THES - The Times Higher Education Supplement World University Rankings, 6 october, 2006.

THES - The Times Higher Education Supplement World University Rankings, 6 october, 2006.

THES - The Times Higher Education Supplement World University Rankings, 9 october, 2008.

WORLD TRADE ORGANIZATION. International Trade Statistics. 2006. Genebra: WTO, 2007.

ZGAGA, Pavel. Looking out: the Bologna Process in a global setting - on the external dimension of the Bologna Process. Oslo: Norwegian Ministry of Education Research, 2006.

SUSAN L. ROBERTSON, doutora em educação pela University of Calcary, Canadá, é professora da Graduate School of Education, University of Bristol, Inglaterra, onde atua como coordenadora do Centre for Globalisation Education and Societies e editora da revista Globalisation, Societies and Education. Publicou, entre outros: A class act: changing teachers'work, globalisation and the State (New York: Garland/Falmer, 2000), Re-imagining and rescripting the future of education: global knowledge economy discourses and the challenge to education systems (Comparative Education, v. 2, n. 41, p. 151-170, 2005); Absences and imaginings: the production of knowledge on globalisation and education (Globalisation, Societies and Education, v. 1, n. 4, p. 303-318, 2006); Embracing the global: crisis and the creation of a new semiotic order to secure Europe's Knowledge-Based Economy (In: FAIRCLOUGH, Norman; WODAK, Ruth; JESSOP, Bob. Education and the Knowledge-Based Economy in Europe. Rotterdam: Sense Publications, 2008. p. 89-108); Parcerias público-privadas, empresas digitais e a produção de um espaco educacional neoliberal em escala europeia (Educação e Pesquisa, v. 3, n. 34, p. 573-586, set./dez. 2008). Pesquisa em andamento: “Globalização, regionalismo, políticas de educação, economia do conhecimento e trabalho docente”.Email: s.l.robertson@bristol.co.uk

Recebido em janeiro de 2009 Aprovado em agosto de 2009 


\section{Resumos/Abstracts/Resumens}

Susan L. Robertson

O processo de Bolonha torna-

se global: modelo, mercado, mobilidade, força intelectual ou estratégia para construção do

\section{Estado?}

O artigo examina a interligação progressiva dos espaços da política de educação superior no mundo, focalizando em particular a Europa e o seu projeto de globalização da educação superior, assim como as implicações do mesmo para outras economias nacionais e regionais. O trabalho começa com o Espaço Europeu de Educação Superior, esboçando as principais características do competitivo projeto europeu na educação superior. Apresenta-se como o Processo Multilateral de Bolonha, projetado para criar uma arquitetura unificada de educação superior na Europa, foi remodelado e dirigido pela estratégia Lisboa 2000 da União Europeia para a competitividade e pelo relançamento da Agenda Lisboa 2005. Essa agenda tem permitido a utilização da educação superior como uma plataforma para amplas estratégias de regionalização e globalização da União Europeia para criar tanto “mentes” quanto “mercados” para a economia europeia de conhecimento, levando à emergência de um sistema global mais integrado e relacional de educação superior. As ações da Europa também são moldadas por seu próprio projeto de construção do Estado, que tende a favorecer a colaboração com as regiões e promover o inter-regionalismo como uma plataforma para a negociação global.

Palavras-chave: Processo de Bolonha; Europa; educação superior; regionalização; globalização.

\section{Europe's Bologna process goes} global: a model, market, mobility, brain power or State building strategy?

This article examines the progressive interlinking of higher education policy spaces around the globe with a particular focus on Europe and its project for globalizing higher education, and the implications of this for other national and regional economies. The text begins with the European Higher Education Area, outlining the key features of the competitive European project in higher education. It traces how the multilateral Bologna Process to create a unified higher education architecture in Europe has been re-shaped and re-directed by the EU's Lisbon 2000 strategy for competitiveness and the re-launching of the Lisbon 2005 agenda. This agenda has allowed higher education to be co-opted as a platform for the European Union's broader strategies of regionalization and globalization to create both "minds" and "markets" for the European knowledge-economy, leading to the emergence of a more integrated and relational global system of higher education. Europe's actions are also shaped by its own state building project which tends to favour engaging with regions and promoting inter-regionalism as a platform for negotiating globally. 
Key words: Bologna Process; Europe; higher education; regionalization; globalization.

\section{El proceso de Bolonia se vuelve} global: modelo, mercado, movilidad, fuerza intelectual, $\dot{c}$ estrategia para la construcción del Estado?

El artículo examina la interconexión progresiva de los espacios de la politica de educación superior, enfocando particularmente a Europa y a su proyecto de globalización de la educación superior, así como las implicaciones del mismo para otras economías nacionales y regionales. El trabajo comienza con el Espacio Europeo de Educación Superior, delineando las principales características del competitivo proyecto europeo en la educación superior. Presentándose como el Proyecto Multilateral de Bolonia, proyectado para crear una arquitectura unificada de educación superior en Europa, fue remodelado y dirigido por la estrategia Lisboa 2000 de la Unión Europea para la competitividad y por el relanzamiento de la Agenda Lisboa 2005. Esta agenda ha permitido la utilización de la educación superior como una plataforma para amplias estrategias de regionalización y globalización de la Unión Europea, para crear tanto "mentes" cuanto "mercados" para la economía europea de conocimiento, llevando a la emergencia de un sistema global más integrado y relacional de educación superior. Las acciones de Europa también son moldeadas por su propio proyecto de construcción del Estado, que tiende a favorecer a la colaboración con las regiones y promover el inter regionalismo como una plataforma para la negociación global.

Palabras claves: Proceso de Bolonia; Europa; educación superior; regionalización; globalización.
Marlene Ribeiro

Trabalho e educação no movimento camponês: liberdade ou emancipação?

O artigo aborda o tema "trabalho, movimentos sociais e educação”. Tem por objetivo trazer elementos para identificar os princípios/fins de liberdade e emancipação que sustentam as experiências de trabalho-educação em sistema de alternância, realizadas pelos movimentos sociais populares do campo. Trata-se das organizações sindicais de trabalhadores rurais e dos movimentos organizados da Via Campesina. Apesar da diversidade de sujeitos, projetos sociais e formas de organização, esses movimentos têm em comum uma luta histórica pela terra de trabalho e pela democracia, o que permite sintetizá-los na unidade movimento camponês. Na importância do estudo destaca-se a necessidade de atentarmos para o novo contido nas experiências de trabalho-educação do movimento camponês, que são produzidas à revelia do processo de reprodução e acumulação do capital e do controle do Estado.

Palavras-chave: trabalho-educação; movimentos sociais; pedagogia da alternância; liberdade e emancipação.

\section{Work and education in the Rural Workers' Movement: freedom or emancipation?}

The article is about work, social movements and education. Its objective is to present elements in order to attempt to identify the principles and ends of freedom and emancipation which sustain experiences of workeducation in a system of alternation, carried out by popular social movements in the countryside. It deals with trade union organizations of rural workers and the movements organized by the Via Campesina. Despite the diversity of subjects, social projects and types of organization, these movements have in common an historical struggle for land on which to work and for democracy, which allow us to synthesize them in the one unit of Rural Workers'Movement. The study is important in that it highlights the need to pay attention to what is new in the experiences of work-education developed by the Rural Workers' Movement, which is produced in the absence of the process of reproduction and accumulation of capital and of State control.

Key words: work-education; social movements; pedagogy of alternation; liberty and emancipation.

¿Trabajo y educación en el movimiento campesino: libertad o emancipación?

El artículo trata del tema "trabajo, movimientos sociales y educación”. Tiene por objetivo traer elementos para identificar los principios y los fines de libertad y emancipación que sostienen las experiencias de trabajo-educación en sistema de alternancia, realizadas por los movimientos sociales populares del campo. Se trata de las organizaciones sindicales de trabajadores rurales $y$ de los movimientos organizados de la Vía Campesina. A pesar de la diversidad de sujetos, proyectos sociales y formas de organización estos movimientos tienen en común una lucha histórica por la tierra de trabajo y por la democracia, lo que nos permite sintetizarlos en la unidad movimiento campesino. En la importancia del estudio se destaca la necesidad de considerar acerca del nuevo contenido en las experiencias de trabajo-educación del movimiento campesino, que son producidas en oposición del proceso de reproducción y de acumulación del capital y del control del Estado.

Palabras claves: trabajo-educación; 